Article

\title{
Fabrication of Crumpled Ball-Like Nickel Doped Palladium-Iron Oxide Hybrid Nanoparticles with Controlled Morphology as Effective Catalyst for Suzuki-Miyaura Coupling Reaction
}

\author{
Seongwan Jang ${ }^{\dagger}$, Taewoo Kim ${ }^{\dagger}$ and Kang Hyun Park * \\ Department of Chemistry and Chemistry Institute for Functional Materials, Pusan National University, \\ Busan 46241, Korea; swjang@chemistry.or.kr (S.J.); spes0@naver.com (T.K.) \\ * Correspondence: chemistry@pusan.ac.kr; Tel.: +82-51-510-2238; Fax: +82-51-980-5200 \\ + These authors contributed equally to this work.
}

Academic Editors: Tian-Yi Ma, Jian-Rong (Jeff) Li and Cláudia Gomes Silva

Received: 13 July 2017; Accepted: 20 August 2017; Published: 24 August 2017

\begin{abstract}
We report a facile synthetic strategy for nickel-doped palladium-iron oxide hybrid nanoparticles with controllable morphology. In this synthetic method, the morphology of the nanoparticles was regulated by the amount of triphenylphosphine used. When $1 \mathrm{mmol}$ of triphenylphosphine was used as a capping agent, the main morphology of the nanoparticles was crumpled balls composed of nanosheets with an average particle size of $215 \mathrm{~nm}$. The nanoparticles showed higher catalytic activity in the Suzuki-Miyaura coupling reaction than did other nanoparticles at equal amounts of Pd. This strategy allowed the reduction of the Pd loading in hybrid nanoparticles while still providing the performance level required for the reaction.
\end{abstract}

Keywords: nanostructured materials; heterocatalysts; hybrid; palladium; nanocatalyst

\section{Introduction}

In recent years, the fabrication of metal hybrid nanoparticles has been widely accepted as one method to increase the catalytic activity, selectivity, and stability of metal nanoparticles [1-3]. The catalytic performances of metal hybrid nanoparticles can be tuned by controlling the elemental distribution in the surface, intermetallic charge transfer, and lattice strain [4]. Hybrid nanoparticles of non-precious metals and noble metals are especially important from the economic point of view for reducing production costs. Hybridization of noble and non-precious metals has improved catalytic activity and increased resistance to poisonous substances [5]. These hybrid nanoparticles have been successfully synthesized using a variety of methods such as galvanic replacement [6], thermal annealing [7], templated growth [8], and microwave-assisted reduction [9].

Among these methods, one of the most successful in terms of controlling the morphology and size of nanoparticles is the solution-phase method [10]. In this method, the use of specific capping agents can have a significant impact on the morphology and size of nanoparticles. The introduction of specific capping agents such as $\mathrm{Br}^{-}$, poly(1-vinylpyrrolidin-2-one), and citrate can affect the energy changes of certain crystal planes and their relative growth rates through chemical interactions with the metal surface [11-13]. Recent studies on the regulation of void sizes and morphologies using triphenylphosphine (TPP) have also been reported [14-16].

According to recent studies, $\mathrm{Pd}$ can be alloyed with $3 \mathrm{~d}$ transition metals $(\mathrm{Cu}, \mathrm{Ni}, \mathrm{Co}, \mathrm{Fe})$, and the catalytic properties of hybrid nanoparticles in various reactions can be superior [17-23]. In particular, $\mathrm{Pd}-\mathrm{Ni}$ alloys have shown excellent catalytic efficiency in various reactions owing to a synergistic 
effect $[24,25]$. This is attributed to the good miscibility between Ni and Pd due to their similar crystal structures and electron configurations [26,27]. In addition, enhancement of the catalytic activity of a Pd alloy through d-band shifts has been demonstrated using density functional theory [28].

Pd-catalyzed carbon-carbon cross-coupling reactions-such as the Suzuki-Miyaura, Heck, and Sonogashira reactions-are important in many types of organic synthesis processes of enormous interest and applications such as those of the chemical and bio industries [29-31]. In particular, the Pd-catalyzed Suzuki-Miyaura reaction of aryl halides with arylboronic acids has been widely used in industry as well as in laboratories owing to its applicability to substrates with a various functional groups and nontoxic by-products [32,33]. Recently, Wu et al. investigated the use of Pd-Ni nanoparticles with a controlled size and morphology in the Suzuki-Miyaura reaction [26]. The Pd-Ni nanoparticles showed higher catalytic activity in this reaction than an equal amount of Pd nanoparticles.

Herein, we report Ni-doped $\mathrm{Pd}-\mathrm{Fe}_{3} \mathrm{O}_{4}$ hybrid nanoparticles (NPFNPs) with a controlled morphology, obtained through one-pot synthesis (Scheme 1), as an effective catalyst system for Suzuki-Miyaura reactions of aryl halides with arylboronic acids. This method enabled the reduction of the Pd loading in hybrid nanoparticles while still providing the performance level required for this reaction.

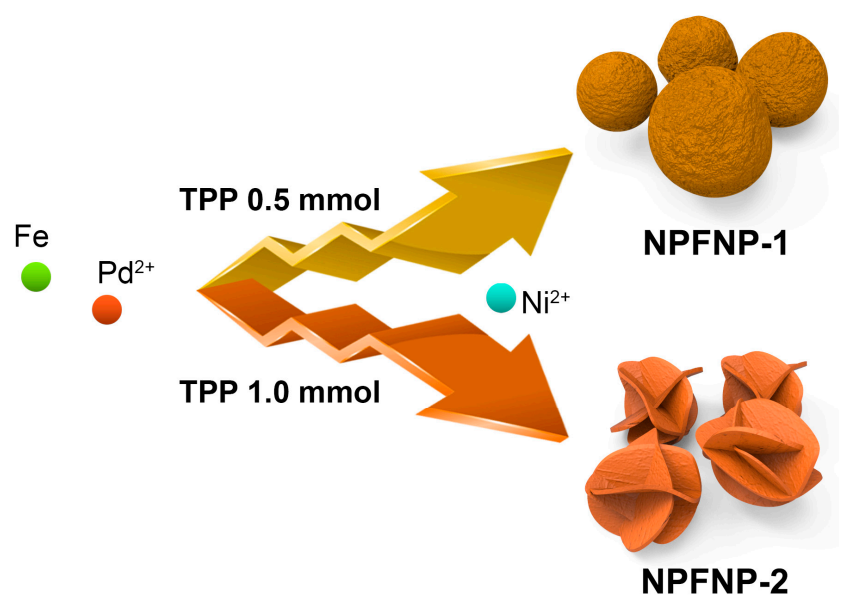

Scheme 1. Illustration of synthesis of NPFNPs with controlled morphology using TPP as capping agent.

\section{Results and Discussion}

$\mathrm{Pd}-\mathrm{Fe}_{3} \mathrm{O}_{4}$ hybrid nanoparticles were synthesized according to a procedure reported in our previous papers $[34,35]$. Then, the NPFNPs were synthesized according to a modification of the procedure described by Lee et al. [36]. A mixture of $\mathrm{Pd}(\mathrm{OAc})_{2}$ and completely dissolved TPP in 1-octadecene and oleylamine was heated at $160{ }^{\circ} \mathrm{C}$ with vigorous magnetic stirring for $30 \mathrm{~min}$. Then, nickel (II) acetylacetonate $\left(\mathrm{Ni}(\mathrm{acac})_{2}\right)$ in oleylamine was syringed dropwise into the mixture. The resultant mixture was further heated at $200{ }^{\circ} \mathrm{C}$ for $30 \mathrm{~min}$. The mixture was cooled down to RT and then centrifuged with hexane and ethanol.

The synthesized nanoparticles took the form of crumpled balls composed of nanosheets (Figure 1). In this method, the morphology of the nanoparticles was regulated by the amount of TPP. When $0.5 \mathrm{mmol}$ of TPP was used for the synthesis, the main morphology of the products (NPFNP-1) was spherical with a rough surface (average particle diameter $=244 \pm 38 \mathrm{~nm}$ ), as shown in Figure 1a,d. When the amount of TPP was increased to $1 \mathrm{mmol}$, the main morphology of the products (NPFNP-2) changed to a more remarkable nanosheet shape at the corners (average particle diameter $=215 \pm 17 \mathrm{~nm}$ ), as shown in Figure 1b,c. High-resolution transmission electron microscopy (HR-TEM) images of individual nanoparticles indicated that the morphology of the nanoparticles is crumpled nanosheets with well-defined fringes (Figure 1e,f). They also revealed line spacings of approximately $0.20 \mathrm{~nm}$ 
for $\mathrm{Pd}$ (111) and approximately $0.29 \mathrm{~nm}$ for $\mathrm{Fe}_{3} \mathrm{O}_{4}$ (220), corresponding to face-centered cubic $\mathrm{Pd}$ and $\mathrm{Fe}_{3} \mathrm{O}_{4}$ structures, respectively. Recently, Wu et al. reported tuning the amount of trioctylphosphine to control the morphology of $\mathrm{PdCu}$ nanoparticles [16]. The amount of capping agent can play an important role in the morphology-controlled synthesis of nanoparticles. Under thermodynamically controlled growth, the capping agent is selectively adsorbed on different facets of the metals, resulting in changes in the surface energy and growth rate of the nanoparticles [37]. When an excess amount was used, however, the crumpled ball morphology of the nanoparticles gradually collapsed. Hence, it was concluded that a proper concentration of TPP is essential for the control of the morphology of the NPFNPs, since the surface coverage of TPP changes with the concentration.

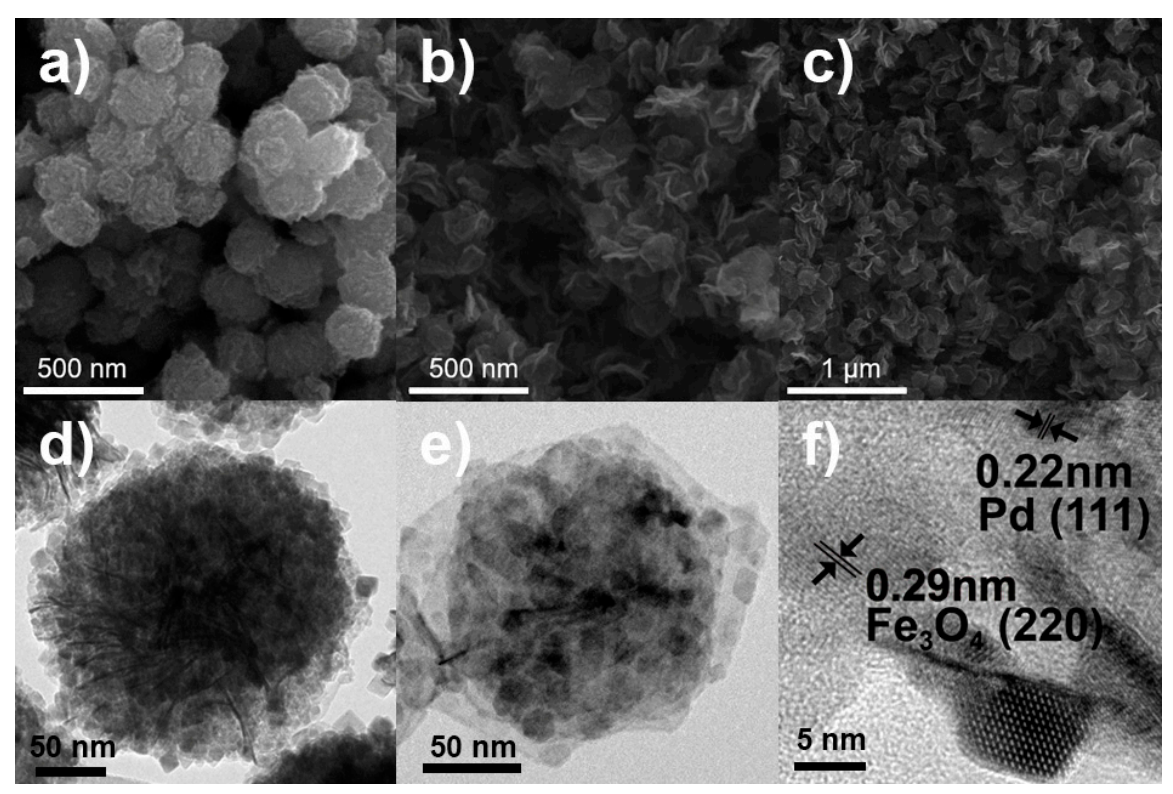

Figure 1. FE-SEM images showing (a,b) NPFNP-2; (c) NPFNP-1 and HRTEM image of NPFNP-2 showing (d) an individual particle; (e) the Pd (111) lattice spacing $(0.20 \mathrm{~nm})$ and (f) the Fe (311) lattice spacing $(0.25 \mathrm{~nm})$.

The high-angle annular dark-field scanning transmission electron microscopy (HAADF-STEM) micrographs and their corresponding energy dispersive X-ray spectroscopy (EDS) mappings show that $\mathrm{Pd}$ and the $3 \mathrm{~d}$ transition metals $(\mathrm{Fe}, \mathrm{Ni}$ ) were well distributed in individual nanoparticles (Figure 2). The metal contents of the fabricated nanoparticles were also measured using inductively coupled plasma atomic emission spectroscopy (ICP-AES) (Table 1). The Pd and Ni contents in NPFNP-2 were slightly higher than those in NPFNP-1. X-ray photoelectron spectroscopy (XPS) was carried out to further measure the chemical composition of NPFNP-2. The XPS spectrum of Pd in Figure 3a shows double peaks at binding energies (BEs) of 335.1 and $340.3 \mathrm{eV}$, corresponding to $\mathrm{Pd}_{3} \mathrm{~d}_{5 / 2}$ and $\mathrm{Pd} 3 \mathrm{~d}_{3 / 2}$, respectively. The BEs of the doublet for $\mathrm{Pd} 3 \mathrm{~d}_{5 / 2}$ and $\mathrm{Pd} 3 \mathrm{~d}_{3 / 2}$ are characteristic of $\mathrm{Pd}^{0}$. Figure $3 b$ shows the XPS signals of the Fe $2 p$ regions, which indicate that $\mathrm{Fe}^{2+}$ and $\mathrm{Fe}^{3+}$ formed $\mathrm{Fe}_{3} \mathrm{O}_{4}$. The spectrum of Fe shows two peaks at around 710.9 and $724.8 \mathrm{eV}$, which could be attributed to Fe $2 p_{3 / 2}$ and $\mathrm{Fe} 2 \mathrm{p}_{1 / 2}$, respectively. The presence of satellite peaks for $\gamma-\mathrm{Fe}_{2} \mathrm{O}_{3}$ at around $719 \mathrm{eV}$ indicated that the $\mathrm{Fe}_{3} \mathrm{O}_{4}$ nanoparticles were partially oxidized. Furthermore, the BE of $2 \mathrm{p}_{3 / 2}(855.4 \mathrm{eV})$, shown in Figure $3 c$, is characteristic of $\mathrm{Ni}^{0}$ and $\mathrm{Ni}^{2+}$. This indicated that the $\mathrm{Ni}$ nanoparticles were partially oxidized owing to exposure to air. 

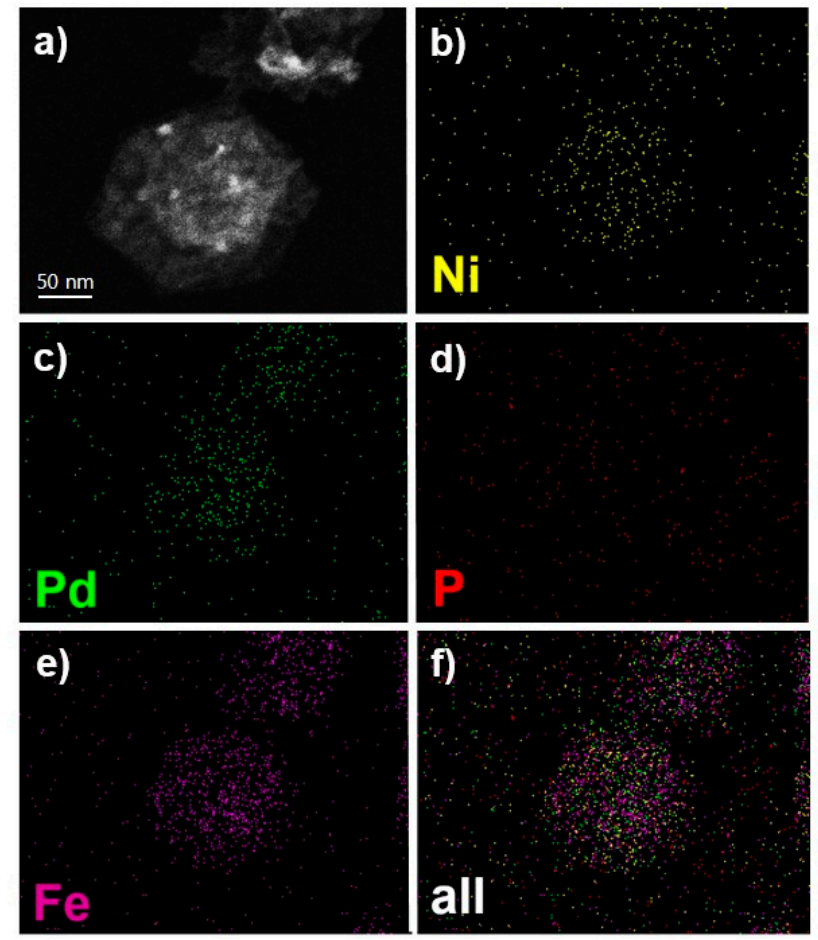

Figure 2. STEM-EDS elemental maps of the NPFNP-2. (a) HAADF-STEM image of the particle; (b-e) elemental maps for $\mathrm{Pd}, \mathrm{Fe}, \mathrm{Ni}$, and $\mathrm{P}$, respectively; (f) images with overlaid maps.

Table 1. ICP-AES data of the fabricated nanoparticles.

\begin{tabular}{cccc}
\hline Nanoparticles & Pd (wt \%) & Fe (wt \%) & Ni (wt \%) \\
\hline NPFNP-1 & 26.68 & 44.47 & 11.23 \\
NPFNP-2 & 27.88 & 42.65 & 12.36 \\
$\mathrm{Pd}^{-F_{3} \mathrm{O}_{4}}$ & 28.5 & 51.11 & - \\
\hline
\end{tabular}
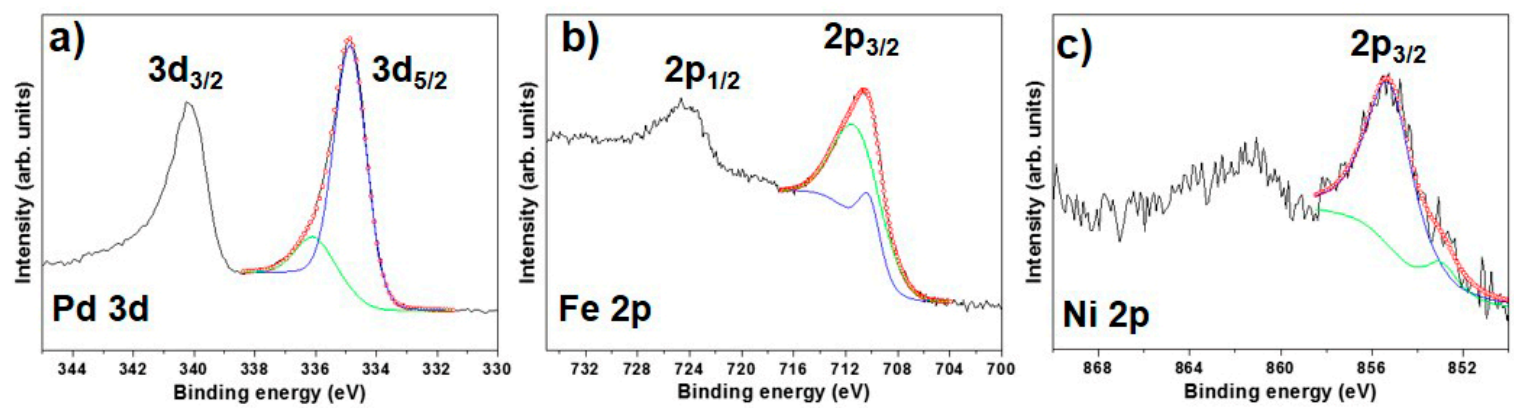

Figure 3. XPS spectra of NPFNP-2 (a) $3 d_{5 / 2}$ and $3 d_{3 / 2}$ lines of Pd; (b) $2 p_{3 / 2}$ and $2 p_{1 / 2}$ lines of Fe; (c) $2 \mathrm{p}_{3 / 2}$ lines of $\mathrm{Ni}$.

Next, we examined the catalytic properties of the nanoparticles in the Suzuki-Miyaura coupling reaction. The Suzuki-Miyaura coupling reaction was carried out using bromobenzene and phenylboronic acid in a mixture of ethanol and water $(1: 1)$ at $50^{\circ} \mathrm{C}$. Potassium carbonate was used as a base to serve as a bridge to connect the substrates and NPFNPs. Figure 4 shows the yields of the products and turnover frequencies (TOFs, defined as the number of molecules produced at each mole of $\mathrm{Pd}$ in the nanoparticles per unit time) for the reactions involving NPFNP-1, NPFNP-2, and $\mathrm{Pd}_{-}-\mathrm{Fe}_{3} \mathrm{O}_{4}$ as the catalyst under the above conditions. The amount of NPFNP-1 used as a catalyst was $0.25 \mathrm{~mol} \%$ of 
nickel relative to the substrate. The amounts of the other nanoparticles were equal to that of NPFNP-1, in terms of their weights. As shown in Figure 4b, NPFNP-2 exhibited relatively high catalytic activity compared to NPFNP-1 and $\mathrm{Pd}-\mathrm{Fe}_{3} \mathrm{O}_{4}$ with the same amount of $\mathrm{Pd}$. The superior catalytic performance of NPFNP-2 can be attributed to a higher number of surface defects due to changes in morphology [38] and synergistic effects of the individual components [39,40]. Additionally, the reaction was carried out using 4-bromoanisole instead of bromobenzene as a substrate to prove that the reaction of catalyzed by NPFNP-2 occurred by cross coupling (Table S1). In this reaction, conversion was lower than that of bromobenzene due to the effect of methoxy, which is an electron donating group. Whether the reaction proceeded by homo coupling or cross coupling was confirmed through the products, and most of the reaction proceeded by cross coupling reaction (selectivity: 97\%). Scheme 2 shows a plausible reaction mechanism for the NPFNP-2-catalyzed Suzuki-Miyaura coupling reaction based on previous works. The surface defects of the nanocatalysts acting as active sites have a significant effect on adsorption and activity during the reactions. Furthermore, since $\mathrm{Pd}$ is negatively charged owing to charge transfer from $\mathrm{Ni}$ to $\mathrm{Pd}$ (electronegativity of $\mathrm{Ni}=1.91, \mathrm{Pd}=2.20$ ) [40], the oxidative addition of the aryl halide is facilitated and the catalytic activity for the reaction is enhanced. For this reason, the morphology changes and the introduction of $\mathrm{Ni}$ led to a reduction in the Pd loading in the hybrid nanoparticles.
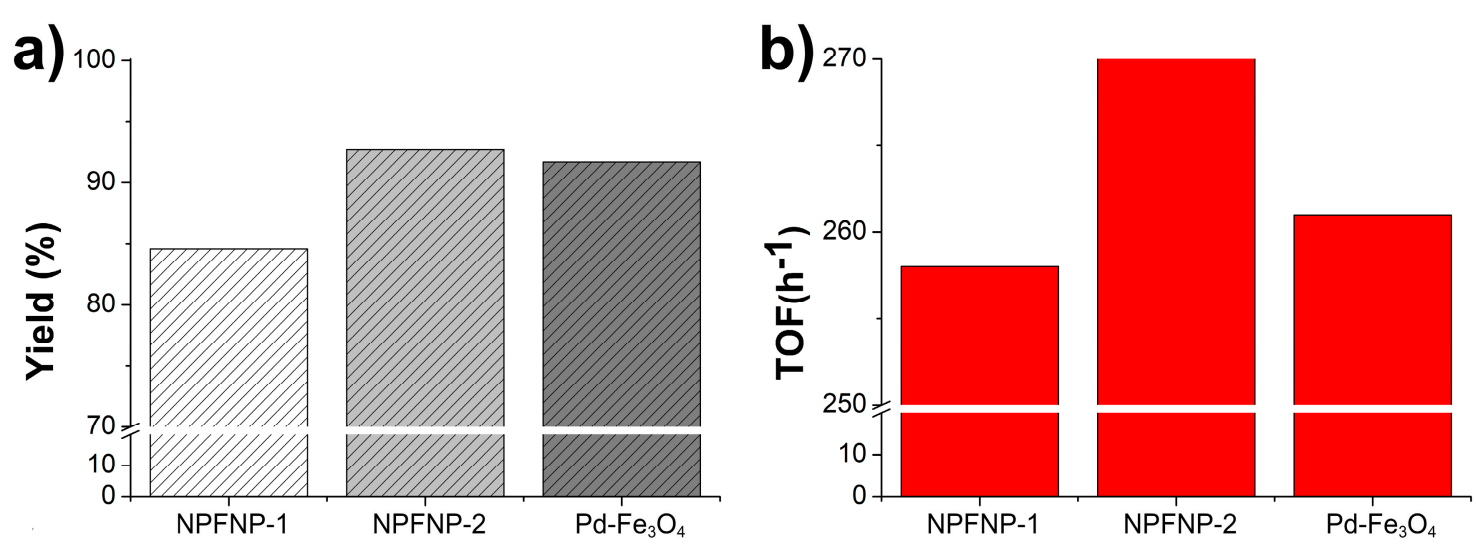

Figure 4. Comparison of (a) yield and (b) TOF (the value was defined as the number of molecules produced at each mole of Pd of nanoparticles per time) for the products in the Suzuki-Miyaura coupling reaction.

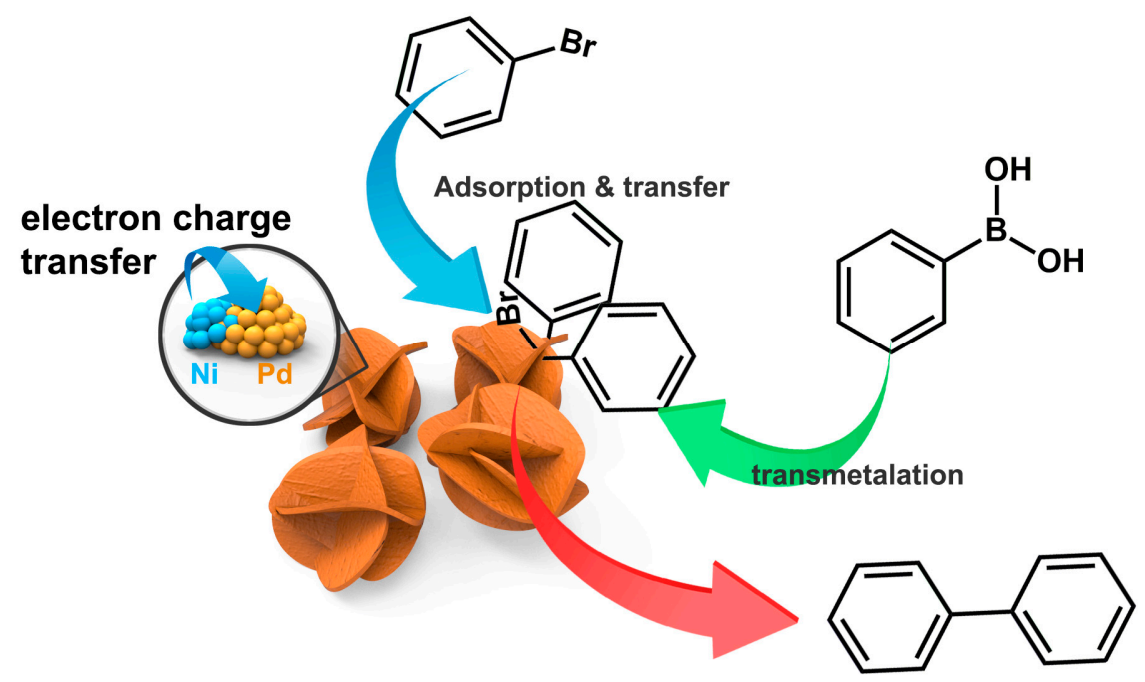

Scheme 2. Schematic illustration of plausible reaction mechanism of the Suzuki-Miyaura cross-coupling reaction catalysed by NPFNP-2. 


\section{Materials and Methods}

\subsection{Materials}

Palladium(II) acetate (Pd(OAc) $2,98 \%$ ), 1-octadecene (ODE, 90\%), oleylamine (OAm, 70\%), iron pentacarbonyl $\left(\mathrm{Fe}(\mathrm{CO})_{5}\right)$, bromobenzene (99\% pure), and phenylboronic acid $(95 \%)$ were purchased from Sigma-Aldrich Inc. (St. Louis, MO, USA). TPP was purchased from Yakuri Pure Chemicals Co. Ltd. (Uji, Japan). Ni(acac) $)_{2}$ was purchased from Fluka Chemical Corp. (Buchs, Switzerland).

\subsection{Typical Synthetic Method of Ni Doped $\mathrm{Pd}_{-} \mathrm{Fe}_{3} \mathrm{O}_{4}$ Hybrid Nanoparticles (NPFNPs)}

NPFNPs were synthesized using a thermal decomposition and reduction method in a solution-phase system. We added 0.131 (for the fabrication of NPFNP-1) or $0.262 \mathrm{~g}$ (for the fabrication of NPFNP-2) of $\mathrm{TPP}$ to $10 \mathrm{~mL}$ of ODE, and the mixture was heated at $80^{\circ} \mathrm{C}$ with vigorous magnetic stirring under an $\mathrm{Ar}$ atmosphere to dissolve the TPP completely. The solution was then cooled down to $60^{\circ} \mathrm{C}$ and a mixture of $0.114 \mathrm{~g}$ of $\mathrm{Pd}(\mathrm{OAc})_{2}$ and $10 \mathrm{~mL}$ of $\mathrm{OAm}$ was added. Then, the mixture was heated to $120^{\circ} \mathrm{C}$ with vigorous magnetic stirring with a heating rate of $6{ }^{\circ} \mathrm{C} \mathrm{min}^{-1}$ and was maintained at this temperature for $30 \mathrm{~min}$. Afterwards, $0.15 \mathrm{~mL}$ of $\mathrm{Fe}(\mathrm{CO})_{5}$ was put into the mixture under an $\mathrm{Ar}$ atmosphere. Then, the mixture was heated to $160{ }^{\circ} \mathrm{C}$ with vigorous magnetic stirring with a heating rate of $4.2{ }^{\circ} \mathrm{C} \mathrm{min}-1$ and was maintained at this temperature for $30 \mathrm{~min}$. For the doping of $\mathrm{Ni}$ on $\mathrm{Pd}_{-}-\mathrm{Fe}_{3} \mathrm{O}_{4}, 0.121 \mathrm{~g}$ of $\mathrm{Ni}(\mathrm{acac})_{2}$ in $10 \mathrm{~mL}$ of $\mathrm{OAm}$ was syringed dropwise into the mixture. The resultant mixture was further heated to $200{ }^{\circ} \mathrm{C}$ with a heating rate of $2.8^{\circ} \mathrm{C} \mathrm{min}^{-1}$ and was maintained at this temperature for $30 \mathrm{~min}$. The resultant mixture was cooled down to room temperature (R.T.), centrifuged with hexane and ethanol twice, and then dried in vacuum.

\subsection{General Procedure for Suzuki-Miyaura Coupling Reactions}

To a $10-\mathrm{mL}$ pressure Schlenk tube we added $1.3 \mathrm{mg}$ of NPFNPs $(0.3 \mathrm{~mol} \%$ with respect to the Pd content of NPFNP-1), $0.10 \mathrm{~mL}$ of bromobenzene $(1.0 \mathrm{mmol}), 0.14 \mathrm{~g}$ of phenylboronic acid $(1.2 \mathrm{mmol}), 0.28 \mathrm{~g}$ of potassium carbonate $(2.0 \mathrm{mmol})$, and $6.0 \mathrm{~mL}$ of a mixture of ethanol and water (1:1). The mixture was stirred vigorously at $50{ }^{\circ} \mathrm{C}$. After $1 \mathrm{~h}$, the catalyst was removed and the reaction mixture was extracted with diethyl ether. Water was removed using $\mathrm{MgSO}_{4}$, and the filtrate was evaporated to give the reaction products. The reaction products were analyzed using gas chromatography/mass spectrometry (GC/MS, QP-2010 SE, Shimadzu, Kyoto, Japan).

\subsection{Catalyst Characterization}

The morphologies and structures of the nanoparticles were examined using high resolutiontransmission electron microscopy (HR-TEM, Tecnai TF30 ST and a Titan ${ }^{3}$ G2 60-300, FEI Company, Hillsboro, OR, USA) and field emission scanning electron microscopy (FE-SEM, CZ/MIRA I LMH, TESCAN, Brno, Czech Republic). Energy-dispersive X-ray spectroscopy (EDS) elemental mapping data were collected using a high-efficiency detection system (Super-X detector). The structural and chemical properties of the nanoparticles were studied using X-ray photoelectron spectroscopy (XPS, Theta Probe, Thermo, Waltham, MA, USA). An inductively coupled plasma-atomic emission spectrometer (ICP-AES, iCAP 6300, Thermo, Waltham, MA, USA) was employed to determine the actual metallic element contents.

\section{Conclusions}

In conclusion, Ni-doped Pd- $\mathrm{Fe}_{3} \mathrm{O}_{4}$ hybrid nanoparticles (NPFNPs) whose morphologies were controlled by tuning the amount of TPP were synthesized through one-pot synthesis. When $1 \mathrm{mmol}$ of TPP was used as a capping agent, the main morphology of the product, NPFNP-2, was prominent crumpled balls composed of nanosheets with an average particle size of $215 \mathrm{~nm}$. NPFNP-2 exhibited higher catalytic activity than did other nanoparticles at the same amount of Pd. The superior 
catalytic performance of NPFNP-2 can be attributed to a higher number of surface defects due to changes in morphology and synergistic effects of the individual components. These results are expected to contribute to the development of economical and effective nanocatalysts that can reduce production costs.

Supplementary Materials: The following are available online at www.mdpi.com/2073-4344/7/9/247/s1, Figure S1: STEM-EDS elemental maps of the NPFNP-1, Figure S2: STEM-EDS elemental maps of the $\mathrm{Pd}_{-}-\mathrm{Fe}_{3} \mathrm{O}_{4}$, Table S1: Suzuki-Miyaura coupling reactions of 4-bromo anisole with phenylboronic acid catalyzed by NPFNP-2.

Acknowledgments: This research was supported by Basic Science Research Program through the National Research Foundation of Korea (NRF) funded by the Ministry of Science, ICT \& Future Planning (NRF-2017R1A4A1015533 and NRF-2017R1D1A1B03036303).

Author Contributions: T.K. designed and performed the experiments; S.J. wrote the paper; K.H.P. was an advisor for the experiment and paper writing.

Conflicts of Interest: The authors declare no conflict of interest.

\section{References}

1. Xiao, C.; Wang, L.L.; Maligal-Ganesh, R.V.; Smetana, V.; Walen, H.; Thiel, P.A.; Miller, G.J.; Johnson, D.D.; Huang, W. Intermetallic $\mathrm{NaAu}_{2}$ as a heterogeneous catalyst for low-temperature co oxidation. J. Am. Chem. Soc. 2013, 135, 9592-9595. [CrossRef] [PubMed]

2. Maligal-Ganesh, R.V.; Xiao, C.X.; Goh, T.W.; Wang, L.L.; Gustafson, J.; Pei, Y.C.; Qi, Z.Y.; Johnson, D.D.; Zhang, S.R.; Tao, F.; et al. A ship-in-a-bottle strategy to synthesize encapsulated intermetallic nanoparticle catalysts: Exemplified for furfural hydrogenation. ACS Catal. 2016, 6, 1754-1763. [CrossRef]

3. Jbir, I.; Couble, J.; Khaddar-Zine, S.; Ksibi, Z.; Meunier, F.; Bianchi, D. Individual heat of adsorption of adsorbed co species on palladium and Pd-Sn nanoparticles supported on $\mathrm{Al}_{2} \mathrm{O}_{3}$ by using temperatureprogrammed adsorption equilibrium methods. ACS Catal. 2016, 6, 2545-2558. [CrossRef]

4. Gu, J.; Zhang, Y.W.; Tao, F.F. Shape control of bimetallic nanocatalysts through well-designed colloidal chemistry approaches. Chem. Soc. Rev. 2012, 41, 8050-8065. [CrossRef] [PubMed]

5. Serov, A.; Kwak, C. Review of non-platinum anode catalysts for DMFC and PEMFC application. Appl. Catal. B Environ. 2009, 90, 313-320. [CrossRef]

6. Chen, J.; Wiley, B.; McLellan, J.; Xiong, Y.; Li, Z.Y.; Xia, Y. Optical properties of Pd-Ag and Pt-Ag nanoboxes synthesized via galvanic replacement reactions. Nano Lett. 2005, 5, 2058-2062. [CrossRef] [PubMed]

7. Kuttiyiel, K.A.; Sasaki, K.; Choi, Y.M.; Su, D.; Liu, P.; Adzic, R.R. Nitride stabilized PtNi core-shell nanocatalyst for high oxygen reduction activity. Nano Lett. 2012, 12, 6266-6271. [CrossRef] [PubMed]

8. Coutts, M.J.; Zareie, H.M.; Cortie, M.B.; Phillips, M.R.; Wuhrer, R.; McDonagh, A.M. Exploiting zinc oxide re-emission to fabricate periodic arrays. ACS Appl. Mater. Interfaces 2010, 2, 1774-1779. [CrossRef] [PubMed]

9. Sarkar, A.; Murugan, A.V.; Manthiram, A. Pt-encapsulated Pd-Co nanoalloy electrocatalysts for oxygen reduction reaction in fuel cells. Langmuir 2010, 26, 2894-2903. [CrossRef] [PubMed]

10. Xia, Y.; Xiong, Y.; Lim, B.; Skrabalak, S.E. Shape-controlled synthesis of metal nanocrystals: Simple chemistry meets complex physics. Angew. Chem. Int. Ed. Engl. 2009, 48, 60-103. [CrossRef] [PubMed]

11. Xiong, Y.J.; Xia, Y.N. Shape-controlled synthesis of metal nanostructures: The case of palladium. Adv. Mater. 2007, 19, 3385-3391. [CrossRef]

12. Sun, Y.G.; Mayers, B.; Herricks, T.; Xia, Y.N. Polyol synthesis of uniform silver nanowires: A plausible growth mechanism and the supporting evidence. Nano Lett. 2003, 3, 955-960. [CrossRef]

13. Ha, T.H.; Koo, H.J.; Chung, B.H. Shape-controlled syntheses of gold nanoprisms and nanorods influenced by specific adsorption of halide ions. J. Phys. Chem. C 2007, 111, 1123-1130. [CrossRef]

14. Chen, X.J.; Cheng, M.; Chen, D.; Wang, R.M. Shape-controlled synthesis of $\mathrm{Co}_{2} \mathrm{P}$ nanostructures and their application in supercapacitors. ACS Appl. Mater. Interfaces 2016, 8, 3892-3900. [CrossRef] [PubMed]

15. Zheng, X.F.; Yuan, S.L.; Tian, Z.M.; Yin, S.Y.; He, J.H.; Liu, K.L.; Liu, L. One-pot synthesis of hollow nickel phosphide nanoparticles with tunable void sizes using triphenylphosphine. Mater. Lett. 2009, 63, 2283-2285. [CrossRef]

16. Wu, D.; Dai, C.; Li, S.; Cheng, D. Shape-controlled synthesis of pdcu nanocrystals for formic acid oxidation. Chem. Lett. 2015, 44, 1101-1103. [CrossRef] 
17. Suo, Y.; Zhuang, L.; Lu, J. First-principles considerations in the design of Pd-alloy catalysts for oxygen reduction. Angew. Chem. Int. Ed. Engl. 2007, 46, 2862-2864. [CrossRef] [PubMed]

18. Liu, S.; Zhang, Q.; Li, Y.; Han, M.; Gu, L.; Nan, C.; Bao, J.; Dai, Z. Five-fold twinned Pd ${ }_{2}$ NiAg nanocrystals with increased surface Ni site availability to improve oxygen reduction activity. J. Am. Chem. Soc. 2015, 137, 2820-2823. [CrossRef] [PubMed]

19. Feng, L.; Chong, H.; Li, P.; Xiang, J.; Fu, F.; Yang, S.; Yu, H.; Sheng, H.; Zhu, M. Pd-Ni alloy nanoparticles as effective catalysts for miyaura-heck coupling reactions. J. Phys. Chem. C 2015, 119, 11511-11515. [CrossRef]

20. Han, S.-H.; Bai, J.; Liu, H.-M.; Zeng, J.-H.; Jiang, J.-X.; Chen, Y.; Lee, J.-M. One-pot fabrication of hollow and porous Pd-Cu alloy nanospheres and their remarkably improved catalytic performance for hexavalent chromium reduction. ACS Appl. Mater. Interfaces 2016, 8, 30948-30955. [CrossRef] [PubMed]

21. Nguyen, L.T.M.; Park, H.; Banu, M.; Kim, J.Y.; Youn, D.H.; Magesh, G.; Kim, W.Y.; Lee, J.S. Catalytic Co 2 hydrogenation to formic acid over carbon nanotube-graphene supported PDNI alloy catalysts. RSC Adv. 2015, 5, 105560-105566. [CrossRef]

22. Wang, Y.; Balbuena, P.B. Design of oxygen reduction bimetallic catalysts: Ab-initio-derived thermodynamic guidelines. J. Phys. Chem. B 2005, 109, 18902-18906. [CrossRef] [PubMed]

23. Ye, W.; Shi, X.; Zhang, Y.; Hong, C.; Wang, C.; Budzianowski, W.M.; Xue, D. Catalytic oxidation of hydroquinone in aqueous solution over bimetallic PdCo catalyst supported on carbon: Effect of interferents and electrochemical measurement. ACS Appl. Mater. Interfaces 2016, 8, 2994-3002. [CrossRef] [PubMed]

24. Nakagawa, Y.; Tomishige, K. Total hydrogenation of furan derivatives over silica-supported Ni-Pd alloy catalyst. Catal. Commun. 2010, 12, 154-156. [CrossRef]

25. Massard, R.; Uzio, D.; Thomazeau, C.; Pichon, C.; Rousset, J.L.; Bertolini, J.C. Strained Pd overlayers on Ni nanoparticles supported on alumina and catalytic activity for buta-1,3-diene selective hydrogenation. J. Catal. 2007, 245, 133-143. [CrossRef]

26. Wu, Y.; Wang, D.; Zhao, P.; Niu, Z.; Peng, Q.; Li, Y. Monodispersed Pd-Ni nanoparticles: Composition control synthesis and catalytic properties in the Miyaura-Suzuki reaction. Inorg. Chem. 2011, 50, 2046-2048. [CrossRef] [PubMed]

27. Son, S.U.; Jang, Y.; Park, J.; Na, H.B.; Park, H.M.; Yun, H.J.; Lee, J.; Hyeon, T. Designed synthesis of atom-economical $\mathrm{Pd} / \mathrm{Ni}$ bimetallic nanoparticle-based catalysts for sonogashira coupling reactions. J. Am. Chem. Soc. 2004, 126, 5026-5027. [CrossRef] [PubMed]

28. Demirci, U.B. Theoretical means for searching bimetallic alloys as anode electrocatalysts for direct liquid-feed fuel cells. J. Power Sources 2007, 173, 11-18. [CrossRef]

29. Balanta, A.; Godard, C.; Claver, C. Pd nanoparticles for C-C coupling reactions. Chem. Soc. Rev. 2011, 40, 4973-4985. [CrossRef] [PubMed]

30. Bumagin, N.A. High-turnover aminopyridine-based Pd-catalysts for Suzuki-Miyaura reaction in aqueous media. Catal. Commun. 2016, 79, 17-20. [CrossRef]

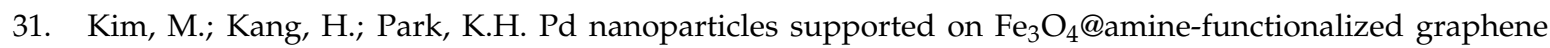
composite and catalytic performance in sonogashira cross-coupling reactions. Catal. Commun. 2015, 72, 150-155. [CrossRef]

32. Le, X.D.; Dong, Z.P.; Jin, Z.C.; Wang, Q.Q.; Ma, J.T. Suzuki-Miyaura cross-coupling reactions catalyzed by efficient and recyclable $\mathrm{Fe}_{3} \mathrm{O}_{4} @ \mathrm{SiO}_{2} @ \mathrm{mSiO}_{2}-\mathrm{Pd}$ (II) catalyst. Catal. Commun. 2014, 53, 47-52. [CrossRef]

33. Fihri, A.; Bouhrara, M.; Nekoueishahraki, B.; Basset, J.M.; Polshettiwar, V. Nanocatalysts for Suzuki cross-coupling reactions. Chem. Soc. Rev. 2011, 40, 5181-5203. [CrossRef] [PubMed]

34. Woo, H.; Park, J.C.; Park, S.; Park, K.H. Rose-like Pd-Fe $\mathrm{O}_{4}$ hybrid nanocomposite-supported Au nanocatalysts for tandem synthesis of 2-phenylindoles. Nanoscale 2015, 7, 8356-8360. [CrossRef] [PubMed]

35. Woo, H.; Kim, D.; Park, J.C.; Kim, J.W.; Park, S.; Lee, J.M.; Park, K.H. A new hybrid nanocatalyst based on $\mathrm{Cu}$-doped $\mathrm{Pd}_{-} \mathrm{Fe}_{3} \mathrm{O}_{4}$ for tandem synthesis of 2-phenylbenzofurans. J. Mater. Chem. A 2015, 3, 20992-20998. [CrossRef]

36. Lee, K.; Kang, S.W.; Lee, S.-U.; Park, K.-H.; Lee, Y.W.; Han, S.W. One-pot synthesis of monodisperse 5 nm Pd-Ni nanoalloys for electrocatalytic ethanol oxidation. ACS Appl. Mater. Interfaces 2012, 4, 4208-4214. [CrossRef] [PubMed]

37. Zhang, H.; Jin, M.S.; Xiong, Y.J.; Lim, B.; Xia, Y.N. Shape-controlled synthesis of Pd nanocrystals and their catalytic applications. Acc. Chem. Res. 2013, 46, 1783-1794. [CrossRef] [PubMed] 
38. He, S.; Li, C.M.; Chen, H.; Su, D.S.; Zhang, B.S.; Cao, X.Z.; Wang, B.Y.; Wei, M.; Evans, D.G.; Duan, X. A surface defect-promoted Ni nanocatalyst with simultaneously enhanced activity and stability. Chem. Mater. 2013, 25, 1040-1046. [CrossRef]

39. Xia, H.W.; Fu, Y.S.; He, G.Y.; Sun, X.Q.; Wang, X. Core-shell-like Ni-Pd nanoparticles supported on carbon black as a magnetically separable catalyst for green Suzuki-Miyaura coupling reactions. Appl. Catal. B Environ. 2017, 200, 39-46. [CrossRef]

40. Rai, R.K.; Gupta, K.; Tyagi, D.; Mahata, A.; Behrens, S.; Yang, X.; Xu, Q.; Pathak, B.; Singh, S.K. Access to highly active Ni-Pd bimetallic nanoparticle catalysts for C-C coupling reactions. Catal. Sci. Technol. 2016, 6, 5567-5579. [CrossRef]

(C) 2017 by the authors. Licensee MDPI, Basel, Switzerland. This article is an open access article distributed under the terms and conditions of the Creative Commons Attribution (CC BY) license (http:/ / creativecommons.org/licenses/by/4.0/). 